\title{
PENURUNAN KADAR GULA DARAH DAN RESIKO ULKUS PADA PENDERITA DIABETES MELLITUS DENGAN SENAM KAKI DIABETES DI PROLANIS PUSKESMAS KESAMBEN KABUPATEN JOMBANG
}

\author{
Heni Maryati $^{1}$, Fitri Firranda Nurmalisyah ${ }^{1}$ \\ ${ }^{1}$ Prodi Diploma III Keperawatan STIKES PEMKAB Jombang \\ Email : nie.maryati@gmail.com
}

\begin{abstract}
ABSTRAK
Langkah penting pertama dalam pengelolaan Diabetes Mellitus (DM) adalah menentukan kadar gula darah yang ingin dicapai agar tidak terjadi komplikasi. Upaya yang dapat dilakukan untuk mencegah terjadinya komplikasi diabetes melitus adalah dengan menerapkan 4 pilar yaitu : pola makan sehat, aktifitas fisik , obat- obatan dan menerapkan pengetahuan (edukasi) harus dilakukan secara beriringan, terstruktur, terukur, terkendali dan berkesinambungan. Latihan fisik merupakan salah satu pilar penatalaksanaan komplikasi diabetes mellitus yang dapat digunakan sebagai salah satu pencegahan kaki diabetik atau ulkus diabetikum yaitu dengan senam kaki diabetes. Pengabdian masyarakat dengan judul penurunan kadar gula darah dan resiko ulkus pada penderita diabetes mellitus dengan senam kaki diabetes di lakukan di Prolanis Puskesmas Kesamben Kabupaten Jombang pada tanggal 30 April 2019 mulai pukul 15.00 - 17.00 . Kegiatan pertama di mulai dengan mempersiapkan daftar hadir, berita acara dan kelengkapan lainnya untuk pelaksanaan, selanjutnya perkenalan, screening pada penderita diabetes mellitus tentang keluhan yang dirasakan, pelaksanaan senam diabetik mellitus, konsultasi tentang senam diabetik mellitus. Dari hasil kegiatan ini di dapatkan 1 orang tidak bisa melakukan senam diabetik mellitus dengan benar dikarenakan sudah terjadi komplikasi pada saraf sehingga kaki kaku dan tidak bisa melaksanakan senam diabetik. Hasil kegiatan ini mampu menjadikan bahan kajian untuk di diskusikan dengan peserta dan keluarga nya agar mereka lebih paham dan secara dini mengenal penyakit yang di deritanya serta mampu mengendalikan terjadinya komplikasi serta di perlu kolaborasikan dengan kader, dan pihak Puskesmas untuk ditindak lanjuti guna mencegah terjadinya komplikasi sehingga dilakukan penanganan awal guna menurunkan angka kesakitan dan kematian akibat penyakit diabetik mellitus
\end{abstract}

Kata kunci : penurunan kadar gula, resiko ulkus, senam kaki diabetes, penderita diabetes

\section{ABSTRACT}

The first important step in the management of Diabetes Mellitus (DM) is to determine the level of blood sugar that you want to achieve to prevent complications. Efforts that can be made to prevent the occurrence of complications of diabetes mellitus are by applying the 4 pillars, namely: healthy eating patterns, physical activity, medicine and applying knowledge (education) must be carried out in tandem, structured, measurable, controlled and continuous. Physical exercise is one of the pillars of the management of diabetes mellitus complications that can be used as one of the prevention of diabetic foot or diabetic ulcer that is with diabetes foot exercises. Community service with the title of reducing blood sugar levels and the risk of ulcers in patients with diabetes mellitus with diabetic foot exercises is done at Prolanis Kesamben Public Health Center in Jombang Regency on April 30, 2019 starting at 15.00- 
17.00. The first activity began by preparing attendance lists, minutes and other completeness for the implementation, then introducing, screening diabetes sufferers about complaints, perceived implementation of diabetic mellitus exercises, consulting about diabetic mellitus exercises. From the results of this activity, it was found that 1 person could not do diabetic mellitus exercises properly due to complications in the nerves so that the legs were stiff and could not carry out diabetic exercises. The results of this activity are able to make the study material to be discussed with participants and their families so that they can better understand and recognize the disease in their early stages and be able to control the occurrence of complications and collaborate with cadres and the Puskesmas to be followed up to prevent complications so early treatment is done in order to reduce morbidity and mortality due to diabetic mellitus

Keywords: decreased sugar levels, risk of ulcers, diabetes foot exercises, diabetics

\section{PENDAHULUAN}

Diabetes mellitus (DM) merupakan salah satu penyakit tidak menular. Penyakit ini disebabkan akibat sekresi insulin mengalami defesiensi yang ditandai dengan kadar gula darah tinggi. Masalah yang sering dialami berupa komplikasi neuropati perifer yang dapat mengakibatkan terjadinya ulkus diabetikum. Sehingga penderita diabetes melitus berrisiko mengalami ulkus diabetikum. Ulkus diabetikum merupakan luka terbuka pada permukaan kulit akibat neuropati, insufisiensi pembuluh darah dan infeksi. Komplikasi lain yang sangat membahayakan dari diabetes mellitus adalah ketidakstabilan kadar gula darah di mana kadar gula darah yang terlalu tinggi terus-menerus dan tidak bisa diabaikan bisa menyebabkan dehidrasi, kerusakan organ dan koma diabetes yang dapat mengancam nyawa.

Langkah penting pertama dalam pengelolaan DM adalah menentukan kadar gula darah yang ingin dicapai. Tujuan dari pengelolaan gula darah untuk mencegah komplikasi DM seperti gangguan jantung, stroke, ginjal, kaki diabetes, gangguan mata,. Upaya yang dapat dilakukan untuk mencegah terjadinya komplikasi diabetes melitus adalah dengan menerapkan 4 pilar yaitu : pola makan sehat, aktifitas fisik, obat- obatan dan menerapkan pengetahuan (edukasi) harus dilakukan secara beriringan, terstruktur, terukur, terkendali dan berksesinambungan. Latihan fisik merupakan salah satu pilar penatalaksanaan komplikasi diabetes mellitus yang dapat digunakan sebagai salah satu pencegahan kaki diabetik atau ulkus diabetikum yaitu dengan senam kaki diabetes (Damayanti, 2018).

Adanya senam kaki diabetes, kaki penderita diabetes melitus dapat terawat dengan baik dan dapat meningkatkan kualitas hidup penderita diabetes mellitus sehingga kadar gula darah juga bisa stabil sehingga terhindar dari komplikasi (Aplihah \& Wulandari, 2017). Berdasarkan Rekapitulasi capaian SPM menurut Puskesmas tribulan ke IV tahun 2017 terdapat lima Puskesmas dengan jumlah penderita diabetes tertinggi yaitu Puskesmas Kesamben (37.89\%), Puskesmas Jabon (29.31\%), Puskesmas Japanan (26.99\%), Puskesmas Keboan (26.67\%) dan Puskesmas Cukir (26.02\%) (Dinkes Jombang, 2017). Sehubungan dengan permasalahan di atas maka kami tertarik untuk melakukan pengabdian masyarakat tentang Penurunan kadar gula darah dan resiko ulkus pada penderita diabetes mellitus dengan senam kaki diabetes di prolanis Puskesmas Kesamben Kabupaten Jombang

\section{METODE PELAKSANAAN}

Pengabdian masyarakat dengan judul penurunan kadar gula darah dan resiko 
ulkus pada penderita diabetes mellitus dengan senam kaki diabetes di lakukan di Prolanis Puskesmas Kesamben Kabupaten Jombang pada tanggal 30 April 2019 mulai pukul 15.00-17.00 . Kegiatan pertama di mulai dengan mempersiapkan daftar hadir, berita acara dan kelengkapan lainnya untuk pelaksanaan, selanjutnya perkenalan, screening pada penderita diabetes mellitus tentang keluhan yang dirasakan, pelaksanaan senam diabetik mellitus, konsultasi tentang senam diabetik mellitus.

\section{HASIL DAN PEMBAHASAN}

Dari hasil kegiatan ini di dapatkan penderita diabetes mellitus mampu melakukan senam diabetik mellitus dan ada 1 orang tidak bisa melakukan senam diabetik mellitus dengan benar dikarenakan sudah terjadi komplikasi pada saraf sehingga kaki kaku dan tidak bisa melaksanakan senam diabetik. Hasil kegiatan ini mampu menjadikan bahan kajian untuk di diskusikan dengan peserta dan keluarga nya agar mereka lebih paham dan secara dini mengenal penyakit yang di deritanya serta mampu melakukan pengendalian komplikasi serta di kolaborasikan dengan kader, dan pihak Puskesmas untuk ditindak lanjuti guna mencegah terjadinya komplikasi sehingga dilakukan penanganan awal guna menurunkan angka kesakitan dan kematian akibat penyakit diabetik mellitus

\section{KESIMPULAN}

Dengan adanya pengabdian masyarakat ini diharapakan menambah pengetahuan dan wawasan peserta, kader, dan pihak puskesmas tentang senam kaki diabetes membuat kaki penderita diabetes melitus dapat terawat dengan baik dan meningkatkan kualitas hidup penderita diabetes mellitus sehingga kadar gula darah juga bisa stabil serta terhindar dari komplikasi penyakit diabetik mellitus guna menurunkan angka kesakitan dan kematian akibat penyakit diabetik mellitus

\section{SARAN}

1. Penderita diabetik mellitus melakukan senam diabetik mellitus secara rutin 3-4 kali seminggu

2. Dengan adanya pengabdian masyarakat ini diharapakan menambah pengetahuan penderita diabetes mellitus tentang penyakit diabetes mellitus dan mampu menerapkan empat pilar pengelolaan diabetes mellitus yaitu pola makan sehat, aktifitas fisik, obatobatan dan menerapkan pengetahuan (edukasi) yang dilakukan secara beriringan, terstruktur, terukur, terkendali dan berksesinambungan untuk mencegah terjadinya komplikasi.

3.Kader dan petugas kesehatan menindaklanjuti peserta yang terdeteksi ada komplikasi pada saraf kaki dengan pemeriksaan rutin di Prolanis dan merujuk ke Puskesmas serta pelayanan kesehatan yang mampu mengatasi penyakit diabetes mellitus

\section{DAFTAR PUSTAKA}

Aplihah, A., \& Wulandari, I. (2017). Pengaruh Senam Kaki Diabetik Dan Terapi Kelereng Terhadap Neuropati Perifer Pasien Diabetes Melitus Tipe II. Faletehan Health Journal, 4(5), 271-276.

Damayanti, S. (2018). Perbedaan Keefektifan Pendidikan Kesehatan Metode Ceramah Dengan Leaflet Terhadap Pengetahuan Dan Sikap Perawatan Kaki Diabetik Di Puskesmas Ngaglik I Sleman Yogyakarta. Jurnal Keperawatan Respati Yogyakarta, 5(1), 331-338.

DinkesJombang. (2017). Profil Kesehatan 2017. Jombang. 